\title{
Tsunami risk mapping simulation for Malaysia
}

\author{
S. Y. Teh ${ }^{1}$, H. L. Koh ${ }^{2}$, Y. T. Moh ${ }^{1}$, D. L. DeAngelis ${ }^{3,4}$ \& J. Jiang ${ }^{4}$ \\ ${ }^{1}$ School of Mathematical Sciences, Universiti Sains Malaysia, Malaysia \\ ${ }^{2}$ Disaster Research Nexus, School of Civil Engineering, \\ Universiti Sains Malaysia, Malaysia \\ ${ }^{3}$ U.S. Geological Survey, Gainesville, Florida, USA \\ ${ }^{4}$ Department of Biology, University of Miami, Florida, USA
}

\begin{abstract}
The 26 December 2004 Andaman mega tsunami killed about a quarter of a million people worldwide. Since then several significant tsunamis have recurred in this region, including the most recent 25 October 2010 Mentawai tsunami. These tsunamis grimly remind us of the devastating destruction that a tsunami might inflict on the affected coastal communities. There is evidence that tsunamis of similar or higher magnitudes might occur again in the near future in this region. Of particular concern to Malaysia are tsunamigenic earthquakes occurring along the northern part of the Sunda Trench. Further, the Manila Trench in the South China Sea has been identified as another source of potential tsunamigenic earthquakes that might trigger large tsunamis. To protect coastal communities that might be affected by future tsunamis, an effective early warning system must be properly installed and maintained to provide adequate time for residents to be evacuated from risk zones. Affected communities must be prepared and educated in advance regarding tsunami risk zones, evacuation routes as well as an effective evacuation procedure that must be taken during a tsunami occurrence. For these purposes, tsunami risk zones must be identified and classified according to the levels of risk simulated. This paper presents an analysis of tsunami simulations for the South China Sea and the Andaman Sea for the purpose of developing a tsunami risk zone classification map for Malaysia based upon simulated maximum wave heights.
\end{abstract}

Keywords: tsunami risk simulation, early warning system. 


\section{Introduction}

Tsunami can be a devastating natural disaster that could inflict great destruction to affected coastal communities. Therefore, proper management systems, including tsunami risk maps, should be developed to address the impact of tsunami. The death toll caused by the 2004 Andaman tsunami is around 250,000 people. Public education, total risk management and coastal zone planning to reduce tsunami hazard were non-existent in the region, resulting in this high death toll. After the 2004 Andaman tsunami, many countries have been working independently and collectively to develop early tsunami warning systems for the affected countries. To provide improved protection against future tsunami, the Ministry of Science Technology and Innovation (MOSTI) of Malaysia established the Malaysian National Tsunami Early Warning System (MNTEWS) at the Malaysian Meteorological Department (MMD) to provide early warning on tsunami generated in the Andaman Sea and the South China Sea that might affect Malaysia. The main objective of MNTEWS is to detect earthquake events that might result in a destructive tsunami and to disseminate accurate and timely warnings so that appropriate actions can be taken. The MNTEWS consists of three components namely: (1) Data and information collection, (2) Data processing and analysis, and (3) Dissemination of early warning regarding tsunami. A network of 14 seismic stations is installed in Malaysia, six in Peninsular Malaysia, five in Sabah and three in Sarawak, for real-time monitoring of earthquake occurrences in the region [1]. To complement the Malaysian network, MMD also receives real-time seismic data from eight seismic stations in Indonesia through VSAT and from 26 seismic stations from other countries through internet. A total of 6 tide gauge stations have been installed at six selected risk areas, with three over the north-western part of Peninsular Malaysia, one in the northeast region of Peninsular Malaysia and two in Sabah, to measure and monitor wave conditions and water elevations along the shores of Malaysia. Three deep ocean buoys are deployed at strategic locations to facilitate early detection of tsunamis. As an integral component of MNTEWS, tsunami risk maps for Malaysia are developed based upon simulations of TUNA to provide critical information regarding areas subject to high risk. This paper briefly presents the risk map and issues related to its development.

\section{TUNA: Tsunami Utilities and Application}

After the 2004 tsunami, a research team in USM immediately initiated a tsunami research program by developing an in-house tsunami simulation model named TUNA. TUNA model simulations enable a better understanding of the mechanism of tsunami generation, propagation and runup. Simulated propagation wave heights from TUNA compare well with results obtained from a well-established model COMCOT [2]. Simulated runup heights also agree generally with measured runup heights of the 2004 tsunami along the northwest 
coast of Peninsular Malaysia [3]. The model TUNA has since been enhanced to allow the assessment of the role of mangrove for coastal protection [4]. The impact of storm surges induced by tsunami or wind-waves on coastal vegetation has also been investigated $[5,6]$. The propagation of tsunami in deep oceans may be simulated by the depth-averaged two-dimensional shallow water equations (SWE), following the proposal of the Intergovernmental Oceanography Commission (IOC). The SWE is applicable when the wave heights are much smaller than the depths of water, which in turn are much smaller than the wavelengths. These conditions are fulfilled for tsunami propagations in the Andaman Sea and the South China Sea. Hence, under normal assumptions typically applicable to tsunami propagations in the deep ocean, the hydrodynamic equations describing the conservation of mass and momentum can be depth averaged [7, 8] and may be written as eqns (1) to (3). Here, discharge fluxes $(M, N)$ in the $x$ - and $y$-directions are related to velocities $u$ and $v$ by the expressions $M=u(h+\eta)=u D, N=v(h+\eta)=v D$, where $h$ is the sea depth and $\eta$ is the water elevation above mean sea level. The numerical approximations of these three equations are available in Koh et al. [3]. Tsunami simulations for the South China Sea are presented next.

$$
\begin{aligned}
& \frac{\partial \eta}{\partial t}+\frac{\partial M}{\partial x}+\frac{\partial N}{\partial y}=0 \\
& \frac{\partial M}{\partial t}+\frac{\partial}{\partial x}\left(\frac{M^{2}}{D}\right)+\frac{\partial}{\partial y}\left(\frac{M N}{D}\right)+g D \frac{\partial \eta}{\partial x} \\
& +\frac{g n^{2}}{D^{7 / 3}} M \sqrt{M^{2}+N^{2}}=0 \\
& \frac{\partial N}{\partial t}+\frac{\partial}{\partial x}\left(\frac{M N}{D}\right)+\frac{\partial}{\partial y}\left(\frac{N^{2}}{D}\right)+g D \frac{\partial \eta}{\partial y} \\
& +\frac{g n^{2}}{D^{7 / 3}} N \sqrt{M^{2}+N^{2}}=0
\end{aligned}
$$

\section{Tsunami simulations in the south China sea}

The USGS has issued a report strongly suggesting the potential risk of tsunami along the entire Pacific subduction zones [9]. It identified the Manila Trench as a high risk tsunamigenic earthquake zone, where the Eurasian plate actively subducts eastward underneath the Luzon volcanic arc on the Philippine Sea plate. This subduction zone can rupture and generate large tsunamis that will have devastating impacts on the affected countries. In the South China Sea (SCS) region, few studies on tsunami threat have been conducted in the past. Based on historical tsunamigenic record for the region, it is believed that potential tsunami sources exist in the region due to the Manila subduction zone seismic activities [10-12]. Various hypothetical earthquake-ruptured faults have been reported for 
the Manila subduction zone $[9,10,13,14]$. The tsunami source considered in this paper is generated by a giant earthquake of magnitude $M_{w}$ above 9 , which is considered as the worst case scenario by Megawati et al. [15]. The adopted fault parameters are derived from studies conducted by Bautista et al. [16] and Wu et al. [17]. The earthquake-ruptured fault consists of a series of 33 segments, each with its own orientation, size and slip magnitude. The initial water surface deformation simulated for the simultaneous rupture of all 33 segments is illustrated in fig. 1 (left). A total of 17 observation points located offshore at depths of about $50 \mathrm{~m}$ are placed near the coasts of the countries fringing the South China Sea to record the TUNA-simulated wave heights and arrival times.
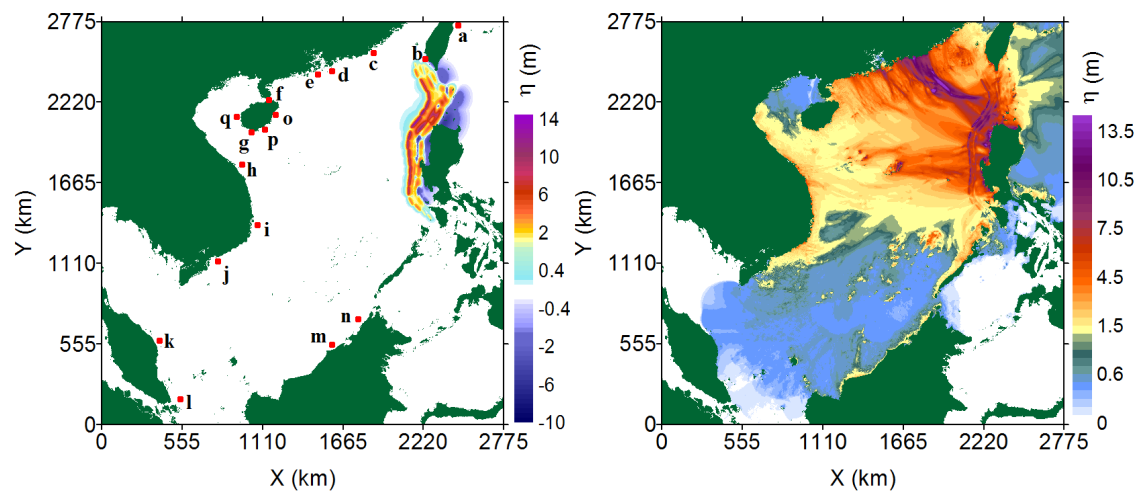

Figure 1: Initial sea surface deformation with observation points (left) and maximum elevation during the first 11 hours of propagation (right) simulated by TUNA.

The simulated maximum wave heights are presented in fig. 1 (right), with higher wave heights recorded along the main propagation axis of the source. Certain locations along the coasts of Philippines, Taiwan, China, and Vietnam receive significant waves. These locations are situated near the tsunami source and directly along the propagation path of the tsunami. On the other hand, countries which are located far away from the Manila Trench receive low tsunami waves. These countries include Peninsular Malaysia and Singapore. Simulated snapshots of the tsunami waves propagating across the South China Sea at various time intervals are shown in fig. 2. The top-left frame in fig. 2 indicates that the waves reach the southern coast of Taiwan in about half an hour. The top-right frame shows the waves heading towards the coasts of China and Vietnam. The bottom-left frame indicates that the waves reach the coasts of China and Vietnam about 2.5 hours after the earthquake. Eight hours after the earthquake, the tsunami waves have passed by the coasts of Sabah and Sarawak, continuing to propagate towards Peninsular Malaysia and Singapore (fig. 2, bottom right). 


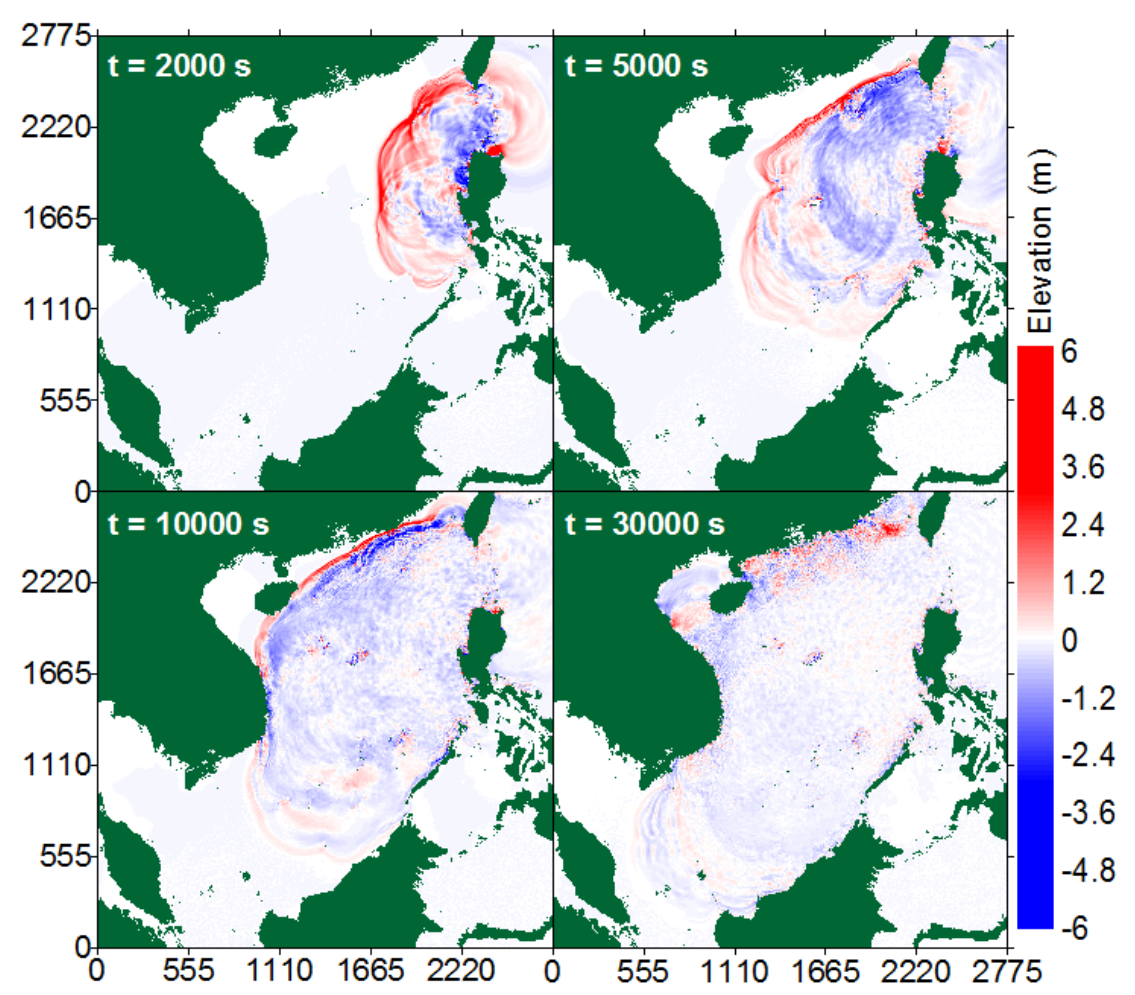

Figure 2: $\quad$ Snapshots of tsunami propagation simulated by TUNA.

Table 1 summarizes the arrival times and the simulated maximum wave heights at the 17 observation points, located offshore at depth of about $50 \mathrm{~m}$. The time series at six chosen observation points are presented in fig. 3. These six locations are Kaoshiung, Sanya, Hong Kong, Da Nang, Miri and Terengganu. The first waves arrive in Kaoshiung after 0.3 hour with maximum offshore height of $1.8 \mathrm{~m}$. Sanya receives maximum waves of $1.5 \mathrm{~m}$ three hours after the earthquake. The tsunami waves arrive offshore of Hong Kong at about 2.6 hours with maximum offshore wave heights of $5.5 \mathrm{~m}$. Da Nang receives maximum offshore wave height of $2 \mathrm{~m}$ after 2.8 hours. The waves arrive offshore of Miri after 2.8 hours with maximum height of $0.3 \mathrm{~m}$. The waves finally reach Terengganu after 9 hours with maximum offshore wave heights of $0.2 \mathrm{~m}$. Simulated wave height at offshore of depth $50 \mathrm{~m}$ might be amplified by an average factor of 2 to 4 as the waves run up the shallow beaches [3, 18]. Accounting for runup amplification, tsunami wave heights along Malaysian coasts are not expected to exceed $1 \mathrm{~m}$. Hence, tsunami risk maps for Malaysia due to tsunamis originating from the Manila Trench are not presented in this paper. 
Table 1: $\quad$ Simulated wave elevation and arrival time of first wave peak at the observation points indicated in fig. 1 (left).

\begin{tabular}{|c|c|c|c|c|c|c|c|}
\hline \multicolumn{2}{|c|}{ Location } & \multirow{2}{*}{$\begin{array}{c}\text { Height } \\
(\mathrm{m}) \\
1.0\end{array}$} & \multirow{2}{*}{$\begin{array}{c}\text { Arrival } \\
\text { time }(\mathrm{h})\end{array}$} & \multicolumn{2}{|r|}{ Location } & \multirow{2}{*}{\begin{tabular}{|c|}
$\begin{array}{c}\text { Height } \\
(\mathrm{m})\end{array}$ \\
0.5
\end{tabular}} & \multirow{2}{*}{$\begin{array}{c}\text { Arrival } \\
\text { time }(\mathrm{h}) \\
5.0\end{array}$} \\
\hline $\mathrm{a}$ & Hualien & & & $\mathrm{j}$ & Vungtau & & \\
\hline $\mathrm{b}$ & Kaoshiung & 1.8 & 0.3 & $\mathrm{k}$ & Terengganu & 0.2 & 9.4 \\
\hline $\mathrm{c}$ & Shantou & 4.0 & 2.6 & 1 & Singapore & 0.1 & 10.4 \\
\hline $\mathrm{d}$ & Hong Kong & 5.5 & 2.7 & $\mathrm{~m}$ & Miri & 0.3 & 2.8 \\
\hline $\mathrm{e}$ & Macau & 4.2 & 3.2 & \multirow{2}{*}{$\mathrm{n}$} & Kota & \multirow{2}{*}{0.4} & \multirow{2}{*}{2.3} \\
\hline $\mathrm{f}$ & Haikou & 0.8 & 4.8 & & Kinabalu & & \\
\hline $\mathrm{g}$ & Sanya & 1.5 & 3.0 & 0 & Qionghai & 1.4 & 2.3 \\
\hline $\mathrm{h}$ & Da Nang & 2.0 & 2.8 & $\mathrm{p}$ & Lingshui & 1.3 & 2.2 \\
\hline $\mathrm{i}$ & Nhatrang & 0.9 & 1.7 & $\mathrm{q}$ & Dongfang & 0.5 & 5.5 \\
\hline
\end{tabular}
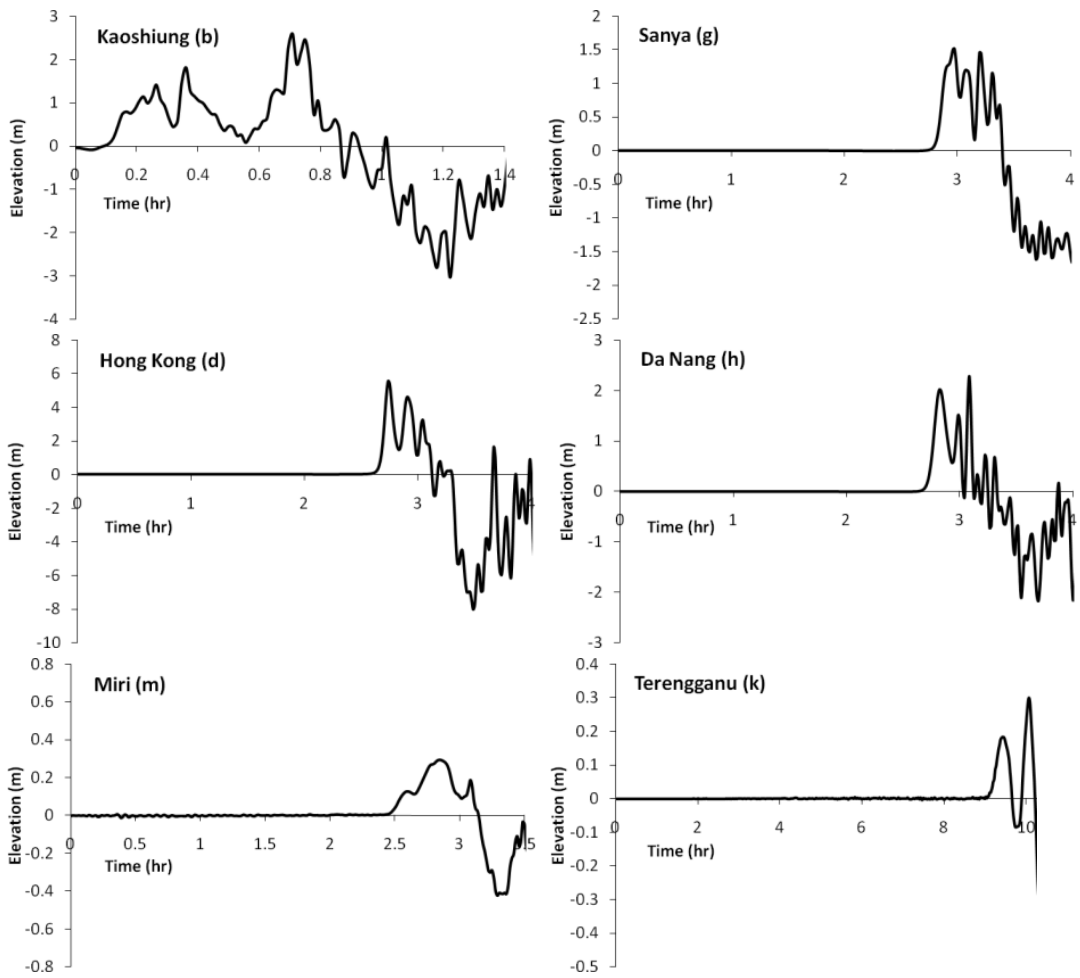

Figure 3: $\quad$ Simulated wave heights off shore at six of the observation points.

During the 2004 Andaman tsunami, beach runup waves measuring up to $4 \mathrm{~m}$ were reported and simulated for the northwest coast of Peninsular Malaysia [3]. Waves exceeding $3 \mathrm{~m}$ are considered as highly dangerous. A total of 68 people 
in Malaysia were killed by this 2004 tsunami. As part of the tsunami preparedness program, simulations are performed for tsunamis originating in the Andaman Sea to investigate the potential impact on the northwest coast of Peninsular Malaysia. These simulations are performed on the basis of several credible tsunami sources [19]. The scenarios of tsunami sources adopted in previous studies did not place Peninsular Malaysia directly on the propagation path of the tsunami. A concern raised is the potential impact of future tsunamis that might result in waves propagating directly towards northwest Peninsular Malaysia. This is currently considered the worst-case scenario, which is addressed in the following section.

\section{Andaman tsunami risk map}

For this worst-case scenario, we consider one single earthquake-ruptured fault of $600 \mathrm{~km}$ in length and $130 \mathrm{~km}$ in width. The fault is oriented in a manner so that the waves would propagate directly towards northwest Peninsular Malaysia. The remaining fault parameters used here are similar to those reported in Koh et al. [3]. Figure 4 shows the time series of the simulated wave heights at offshore locations with depth of $50 \mathrm{~m}$ at three selected points, namely Penang (A), Langkawi (B) and Phuket (C). The locations of A, B and C are indicated in fig. 5. Maximum offshore wave height of about $8 \mathrm{~m}$ is recorded at Phuket, arriving about 1.8 hours after the earthquake (fig. 4, right). Penang and Langkawi may be hit by offshore waves up to $2 \mathrm{~m}$ about three hours after the earthquake (fig. 4 , left and middle). It should be noted the waves of $2 \mathrm{~m}$ offshore may be amplified to runup heights of 4-8 $\mathrm{m}$ along the beaches, based upon the mean amplification factors of 2 to 4 . Hence, Penang and Langkawi might receive height up to $8 \mathrm{~m}$ along the beaches. The amplification factor depends on the topography and bathymetry at the coastal zones. The initial water displacement generated by this fault rupture is shown in fig. 5 (top left). Subsequent propagation of the tsunami waves is illustrated in a series of snapshots in fig. 5. Comparison between simulated maximum wave heights for this worst case scenario and the 2004 Andaman tsunami are illustrated in fig. 6. The orientation of the source in this worst case scenario directs the waves toward the coasts of northwest Peninsular Malaysia, leading to high wave heights along these coasts as compared to the 2004 tsunami.
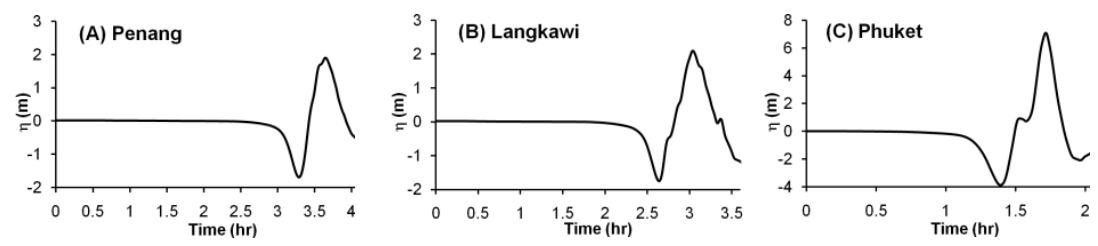

Figure 4: Simulated wave heights off shore near Penang, Langkawi and Phuket. 
10 Disaster Management and Human Health Risk II

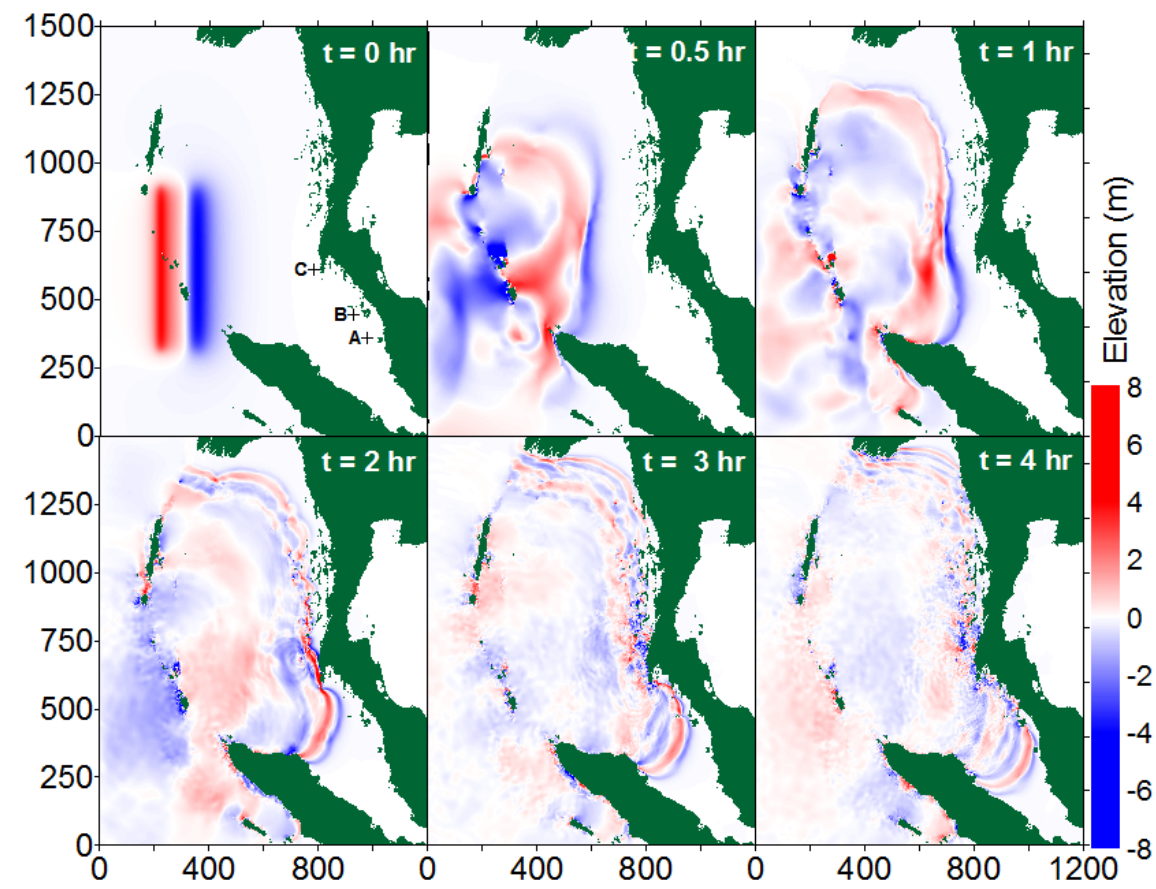

Figure 5: Snapshots of tsunami propagation generated by a source in the Andaman Sea.

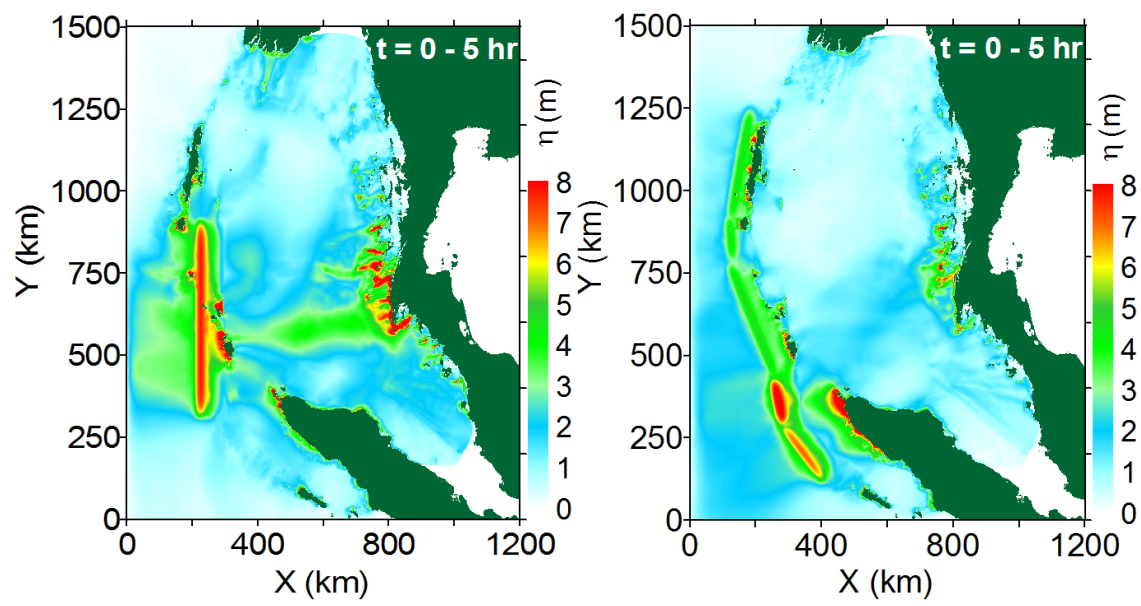

Figure 6: Simulated maximum wave heights during the first 5 hours for the worst case scenario (left) and the 2004 Andaman tsunami (right). 


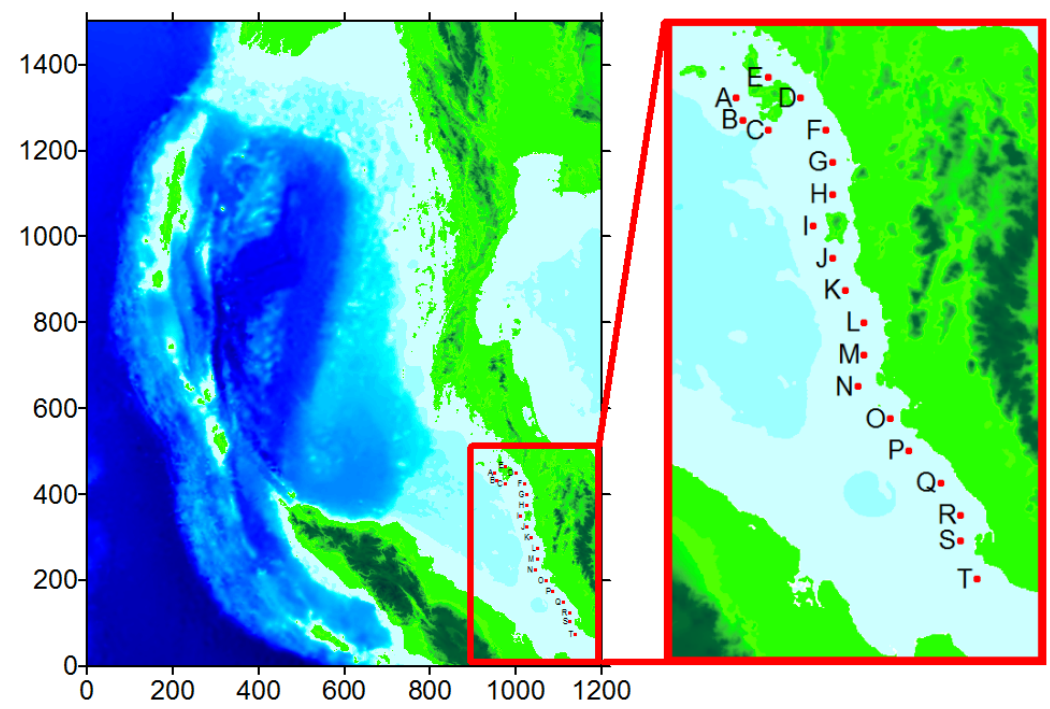

Figure 7: Bathymetry and observation points placed along northwest Peninsular Malaysia for tsunami hazard analysis.

Table 2: $\quad$ Simulated maximum wave heights for the worst case scenario at the twenty observation points shown in fig. 7.

\begin{tabular}{|c|c|c|c|c|c|c|c|c|c|}
\hline \multicolumn{10}{|c|}{ Maximum Wave Height (m) } \\
\hline $\mathrm{A}$ & $\mathrm{B}$ & $\mathrm{C}$ & $\mathrm{D}$ & $\mathrm{E}$ & $\mathrm{F}$ & $\mathrm{G}$ & $\mathrm{H}$ & $\mathrm{I}$ & $\mathrm{J}$ \\
\hline 1.8 & 1.9 & 2.4 & 0.8 & 0.9 & 4.6 & 2.6 & 1.8 & 2.6 & 2.4 \\
\hline $\mathrm{K}$ & $\mathrm{L}$ & $\mathrm{M}$ & $\mathrm{N}$ & $\mathrm{O}$ & $\mathrm{P}$ & $\mathrm{Q}$ & $\mathrm{R}$ & $\mathrm{S}$ & $\mathrm{T}$ \\
\hline 1.8 & 1.5 & 1.3 & 1.8 & 3.9 & 1.1 & 0.9 & 0.3 & 0.15 & 0.1 \\
\hline
\end{tabular}

Table 3: $\quad$ Simulated arrival times for the worst case scenario at the twenty observation points shown in fig. 7 .

\begin{tabular}{|c|c|c|c|c|c|c|c|c|c|}
\hline \multicolumn{10}{|c|}{ Arrival time (hr) } \\
\hline $\mathrm{A}$ & $\mathrm{B}$ & $\mathrm{C}$ & $\mathrm{D}$ & $\mathrm{E}$ & $\mathrm{F}$ & $\mathrm{G}$ & $\mathrm{H}$ & $\mathrm{I}$ & $\mathrm{J}$ \\
\hline 3.25 & 3.35 & 3.57 & 4.54 & 3.73 & 4.75 & 4.44 & 4.32 & 4.27 & 4.45 \\
\hline $\mathrm{K}$ & $\mathrm{L}$ & $\mathrm{M}$ & $\mathrm{N}$ & $\mathrm{O}$ & $\mathrm{P}$ & $\mathrm{Q}$ & $\mathrm{R}$ & $\mathrm{S}$ & $\mathrm{T}$ \\
\hline 4.65 & 4.94 & 5.00 & 5.12 & 6.07 & 6.3 & 6.72 & 7.11 & 7.18 & 7.53 \\
\hline
\end{tabular}

For the purpose of communicating tsunami risks to local communities and local authorities, tsunami risk maps are developed. The tsunami hotspots identified are located in northwest Peninsular Malaysia as shown in fig. 7. Twenty observation points are placed along the hotspots to record the maximum simulated wave heights. Tables 2 and 3 show respectively the maximum offshore 
Table 4: Tsunami index ranking system adopted for northwest coast of Peninsular Malaysia.

\begin{tabular}{|l|l|l|l|l|l|}
\hline Variables & $\begin{array}{l}\text { Very Low } \\
1\end{array}$ & $\begin{array}{l}\text { Low } \\
2\end{array}$ & $\begin{array}{l}\text { Moderate } \\
3\end{array}$ & $\begin{array}{l}\text { High } \\
4\end{array}$ & $\begin{array}{l}\text { Very High } \\
5\end{array}$ \\
\hline $\begin{array}{l}\text { Maximum } \\
\begin{array}{l}\text { Tsunami } \\
\text { Height }\end{array}\end{array}$ & $<0.5 \mathrm{~m}$ & $0.5-1.0 \mathrm{~m}$ & $1.0-2.0 \mathrm{~m}$ & $2.0-3.0 \mathrm{~m}$ & $>3.0 \mathrm{~m}$ \\
\hline
\end{tabular}

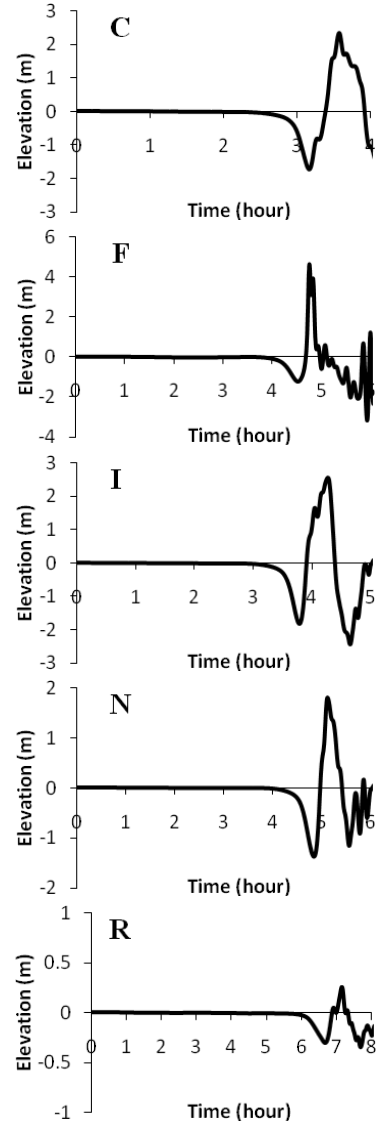

Figure 8: Time series of the simulated wave heights at Langkawi (C), Kuala Kedah (F) Penang (I), Pangkor island $(\mathrm{N})$ and Kuala Selangor (R).

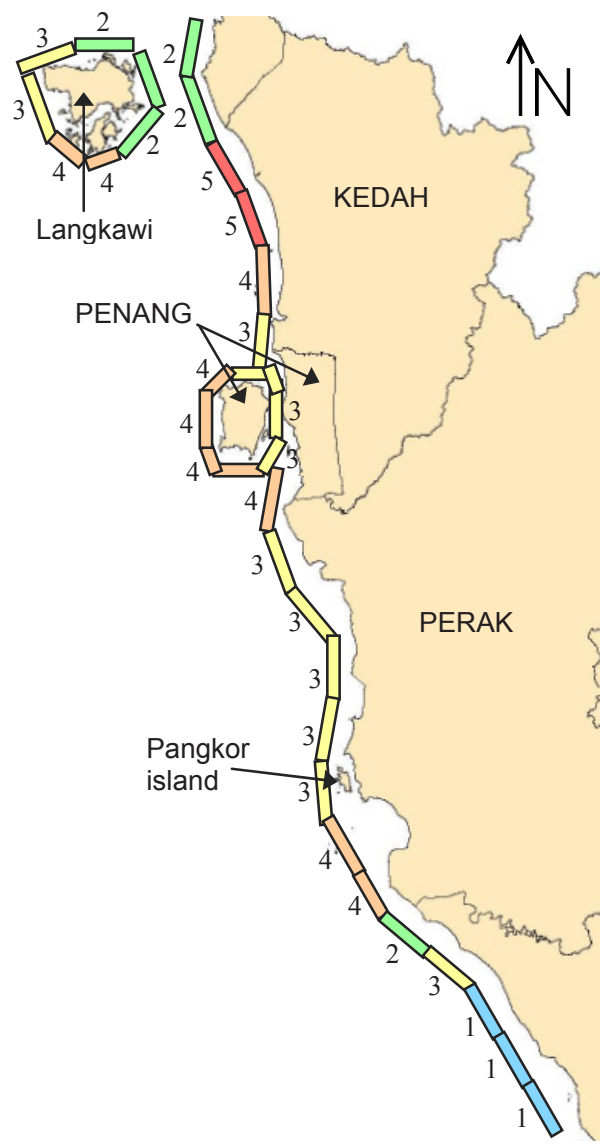

Figure 9: Tsunami hazard map using the index ranking system in table 4. The numbers indicate tsunami risk along the coast under the worst case scenario (1 - very low; 2 - low; 3 - moderate; 4 high; 5 - very high). 
wave heights and arrival times at the 20 observation points. These simulated wave heights are then used to develop the tsunami risk map following the tsunami index ranking system shown in table 4, based upon maximum wave heights at offshore locations with depth of $50 \mathrm{~m}$. Time series of simulated tsunami waves at selected locations namely Langkawi, Kuala Kedah, Penang, Pangkor island and Kuala Selangor are shown in fig. 8. Based upon this worst case scenario, the tsunami risk map developed is shown in fig. 9.

\section{Conclusion}

This paper has presented tsunami simulation results for two mega tsunamis originating from the South China Sea and the Andaman Sea. Tsunami risk map is presented for the worst-case tsunami due to submarine earthquake in the Andaman Sea.

\section{Acknowledgements}

Financial support provided by Grants 1001/PMATHS/817024, 1001/PMATHS/817025 and 1001/PMATHS/811093 is gratefully acknowledged.

\section{References}

[1] Koh, H.L., Teh, S.Y., Liu, P.L.-F. \& Che Abas, M.R., Tsunami simulation research and mitigation programs in Malaysia post 2004 Andaman tsunami (Chapter 2). Tsunamis: Causes, Characteristics and Warnings, and Protection, eds. Neil Veitch and Gordon Jaffray, Nova Science Publishers, Inc., Hauppauge, New York, pp. 29-56, 2010.

[2] Liu, P.L.-F., Woo, S.B., Cho, Y.S., Computer Programs for Tsunami Propagation and Inundation, Cornell University, New York, 104 p., 1998.

[3] Koh, H.L., Teh, S.Y., Liu, P.L.-F., Izani, A.M.I. \& Lee, H.L., Simulation of Andaman 2004 tsunami for assessing impact on Malaysia. Journal of Asian Earth Sciences, 36(1), pp. 74-83, 2009.

[4] Teh, S.Y., Koh, H.L., P.L.-F, Liu., Izani, A.M.I. \& Lee, H.L., Analytical and numerical simulation of tsunami mitigation by mangroves in Penang, Malaysia. Journal of Asian Earth Sciences, 36(1), pp. 38-46, 2009.

[5] Sternberg, L., Teh, S.Y., Ewe, S., Miralles-Wilhelm, F.R. \& DeAngelis, D., Competition between hardwood hammocks and mangroves. Ecosystems, 10(4), pp. 648-660, 2007.

[6] Teh, S.Y., DeAngelis, D., Sternberg, L., Miralles-Wilhelm, F.R., Smith, T.J. \& Koh, H.L., A simulation model for projecting changes in salinity concentrations and species dominance in the coastal margin habitats of the Everglades. Ecological Modelling, 213(2), pp. 245-256, 2008.

[7] IOC, Numerical method of tsunami simulation with the leap frog scheme, 1 , shallow water theory and its difference scheme. Manuals and Guides of 
the IOC, Intergovernmental Oceanography Commission (IOC), UNESCO, Paris, pp. 12-19, 1997.

[8] Hérbert, H., Schindelé, F., Altinok, Y., Alpar, B. \& Gazioglu, C., Tsunami hazard in the Marmara Sea (Turkey): a numerical approach to discuss active faulting and impact on the Istanbul coastal areas. Marine Geology, 215, pp. 23-43, 2005.

[9] Kirby, S., Geist, E.L., Lee, W.H.K., Scholl, D. \& Blakely, R., Tsunami source characterization for western Pacific subduction zones: A preliminary report, Tsunami Sources Workshop, 2006, http://walrus.wr.usgs.gov/ tsunami/workshop/.

[10] Liu, Y., Santos, A., Wang, S.M., Shi, Y., Liu, H. \& Yuen, D.A., Tsunami hazards along Chinese coast from potential earthquakes in South China Sea. Physics of the Earth and Planetary Interiors, 163, pp. 233-244, 2007.

[11] Liu, P.L.-F., Wang, X.M. \& Salisbury, A.J., Tsunami hazard and early warning system in South China Sea. Journal of Asian Earth Sciences, 36(1), pp. 2-12, 2009.

[12] Ramos , N.T. \& Tsutsumi , H., Evidence of large prehistoric offshore earthquakes deduced from uplifted Holocene marine terraces in Pangasinan Province, Luzon Island, Philippines. Tectonophysics, 495, pp. 145-158, 2010.

[13] Dao, M.H., Tkalich, P., Chan, E.S. and Megawati, K., Tsunami propagation scenarios in the South China Sea. Journal of Asian Earth Sciences, 36(1), pp. 67-73, 2009.

[14] Ruangrassamee, A. \& Saelem, N., Effect of tsunamis generated in the Manila Trench on the Gulf of Thailand. Journal of Asian Earth Sciences, 36(1), pp. 56-66, 2009.

[15] Megawati, K., Shaw, F., Sieh, K., Huang, Z., Wu, T.-R., Lin, Y., Tan, S.K. \& Pan, T.-C., Tsunami hazard from the subduction megathrust of the South China Sea: Part I. Source characterization and the resulting tsunami Journal of Asian Earth Sciences, 36(1), pp. 13-20, 2009.

[16] Bautista, C.B., Bautista, M.L.P., Oike, K., Wu, F.T. \& Punongbayan, R.S., A new insight on the geometry of subducting slabs in northern Luzon, Philippines. Tectonophysics, 339, pp. 279-310, 2001.

[17] Wu, Y.M., Chang, C.H., Zhao, L., Shyu, J.B.H., Chen, Y.G., Sieh, K. \& Avouac, J.P., Seismic tomography of Taiwan: improved constraints from a dense network of strong motion stations. Journal of Geophysical Research-Solid Earth, 112, (B08312), 2007.

[18] Pelinovsky, E., Kharif, C., Riabov, I. \& Francius, M., Modelling of Tsunami Propagation in the Vicinity of the French Coast of the Mediterranean. Natural Hazards, 25(2), pp. 135-159, 2002.

[19] Koh, H.L., Teh, S.Y., Izani, A.M.I., Lee, H.L. \& Kew, L.M., Simulation of future Andaman tsunami into Straits of Malacca by TUNA. Journal of Earthquakes and Tsunamis, 3(2), pp. 89-100, 2009. 